\title{
Familial hypercholesterolaemia
}

\author{
A guide for general practice
}

Tom Brett, Diane Arnold-Reed

This guide provides a practical approach to making a clinical, phenotypic diagnosis of familial hypercholesterolaemia (FH) in general practice. Although FH is a common, hereditary, autosomal dominant disorder of lipid metabolism, ${ }^{1}$ it is often not identified in clinical practice. ${ }^{2,3}$ This guide explains when a possible diagnosis of $\mathrm{FH}$ should be considered and suggests clinical signs and symptoms to look for and the treatment pathway for patients. It includes suggestions for follow-up of close family members and for diagnosis and management of children.

\section{When to consider familial hypercholesterolaemia}

FH should always be considered in adults with a total cholesterol level of $\geq 7.5 \mathrm{mmol} / \mathrm{L}$ or a low-density lipoprotein cholesterol (LDL-C) level of $\geq 5.0 \mathrm{mmol} / \mathrm{L}$, especially if there is a personal or family history of premature coronary heart disease (CHD). ${ }^{4,5}$

\section{How to make a phenotypic diagnosis \\ In Australia, the Dutch Lipid Clinic Network Score (DLCNS; Table 1) is used to make a probable or definite clinical diagnosis of $\mathrm{FH}$ on the basis of phenotypic criteria. The DLCNS is based on several key factors including}

the patient's family history of premature cardiovascular disease (CVD), their personal CVD history, their untreated LDL-C levels and physical stigmata such as tendon xanthomas or arcus cornealis.

A DLCNS of 6-8 indicates 'probable' $\mathrm{FH}$, while a total score $>8$ indicates 'definite' FH. DNA testing that reveals a functional mutation in $L D L R, A P O B$ or PCSK9 yields an FH score of eight. A negative genetic test does not exclude $\mathrm{FH}$ because more than 2000 mutations of LDLR exist. ${ }^{2-4}$

\section{Clinical signs}

Tendon xanthomas are white or yellow lumps of cholesterol deposits found around knuckles or Achilles tendons (Figures 1A, 1B). They are rarely seen in general practice but are pathognomonic for $\mathrm{FH}$.

Corneal arcus is a circular deposit of lipid material at the edge of the cornea (Figure 1C). In young people aged $<45$ years, ${ }^{2}$ it is suggestive of $\mathrm{FH}$.

Xanthelasma is a yellowish deposit of lipid material found around the eyelid or medial canthus area. It may indicate high cholesterol levels but not necessarily FH (Figure 1D).

\section{Advising patients of familial hypercholesterolaemia diagnosis Patients with a DLCNS $\geq 6$ should be advised they have a phenotypic diagnosis of FH. It is recommended that they are provided with information about how the condition is inherited from parents to}

children within families, ${ }^{1}$ the treatment options available and future management options. Because FH is hereditary, dietary and lifestyle measures alone are not sufficient to manage the condition; however, lifestyle modification may be helpful, especially avoidance of smoking. ${ }^{5}$

It is recommended to advise patients that if $\mathrm{FH}$ is left untreated, up to half will have a fatal or non-fatal CVD event by the age of 50 years (men) or 60 years (women). ${ }^{4,5}$ It may be helpful to offer patients an 'open door' policy to consider your advice and return at any time. $\mathrm{FH}$ results in very high levels of LDL-C from birth. If untreated, this cholesterol burden remains throughout life, accelerating premature CVD, especially myocardial infarction and angina, by 3-4 decades. ${ }^{1-4}$ Early diagnosis and treatment offer the best opportunity to enable affected patients to live a normal lifespan. ${ }^{2,3}$

\section{Treatment}

Once a diagnosis of $\mathrm{FH}$ is confirmed, lipid-lowering treatment (usually a statin, eg $20 \mathrm{mg}$ rosuvastatin or $40 \mathrm{mg}$ atorvastatin) should be commenced. ${ }^{6}$ The aim is to lower LDL-C by $\geq 50 \% .^{3,5}$ Dietary and lifestyle advice, especially avoidance of smoking, is recommended. Close family relatives are encouraged to have their lipids checked as part of a cascade testing process; half the patient's first-degree relatives will also have the condition..$^{2,4,7}$

If symptoms or signs of CVD exist, they should be noted and patients referred for specialist investigation. Asymptomatic 
patients should commence lipid-lowering treatment. Six weeks later, a full blood examination can measure the reduction in LDL-C, and the patient's medication may be titrated accordingly. ${ }^{4,6,8}$

\section{Follow-up}

All patients with FH should be regularly followed up with at least an annual review. ${ }^{5}$ Compliance may be difficult, especially in younger, asymptomatic patients. ${ }^{8}$

\section{Table 1. Dutch Lipid Clinic Network Criteria scoring for diagnosis of familial} hypercholesterolaemia

\section{Criteria}

\section{Family history}

First-degree relative with known premature coronary and/or vascular disease (men aged $<55$ years, women aged $<60$ years)

or

First-degree relative with known LDL-C above the 95th percentile for age and sex

First-degree relative with tendinous xanthomata and/or arcus cornealis or

Children aged $<18$ years with LDL-C above the 95th percentile for age and sex

\section{Clinical history}

Patients with premature coronary artery disease (men aged $<55$ years, women aged $<60$ years)

Patients with premature cerebral or peripheral vascular disease (men aged $<55$ years, women aged $<60$ years)

Physical examination

Tendinous xanthomata

Arcus cornealis before 45 years of age

\section{Investigation}

\section{LDL-C}

\begin{tabular}{lc}
\hline$\geq 8.5 \mathrm{mmol} / \mathrm{L}$ & 8 \\
\hline $6.5-8.4 \mathrm{mmol} / \mathrm{L}$ & 5 \\
\hline $5.0-6.4 \mathrm{mmol} / \mathrm{L}$ & 3 \\
\hline $4.0-4.9 \mathrm{mmol} / \mathrm{L}$ & 1 \\
\hline DNA analysis & \\
\hline
\end{tabular}

Functional mutation in $\angle D L R, A P O B$ or $P C S K 9$ genes

\section{Stratification}

Total score

Definite $\mathrm{FH}$

Probable FH

Possible FH

Adapted from the National Institute for Health and Clinical Excellence and the National Collaborating Centre for Primary Care 5

FH, familial hypercholesterolaemia; LDL-C, low-density lipoprotein cholesterol
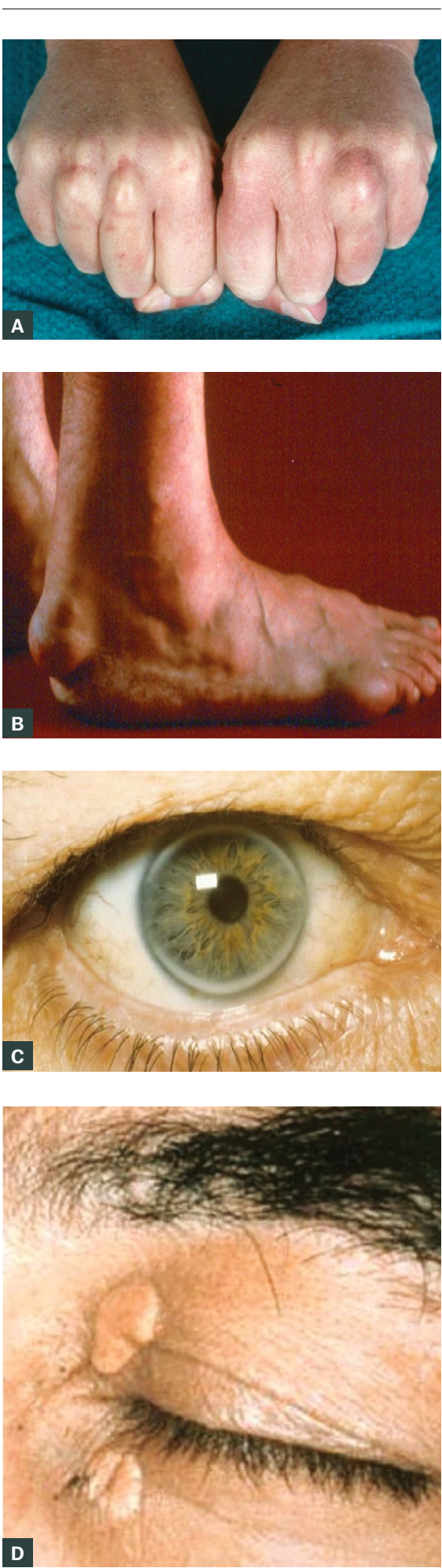

Figure 1. Clinical signs of familial hypercholesterolaemia. A. Xanthoma knuckles; B. Xanthoma Achilles tendon; C. Arcus cornealis; D. Xanthelasma medial canthus 
Follow-up checks allow opportunities to help identify any signs or symptoms of emerging CVD and arrange investigations. Medication side effects can also be monitored and ongoing treatment encouraged. ${ }^{5}$

Women of childbearing age should avoid statins for at least three months before conception and during pregnancy. ${ }^{2,4}$ Alternative approaches will be required, and specialist involvement in managing the patients' FH should be ensured.

\section{Diagnosis in children}

Diagnosis of FH in children ideally occurs before the age of 10 years. ${ }^{3-5}$ However, diagnosis may need to occur by three years of age if both parents have $\mathrm{FH}$ and the risk of homozygous $\mathrm{FH}$ exists. ${ }^{3}$ If there is strong suspicion of $\mathrm{FH}$ in a family, blood levels for LDL-C should be repeated post-puberty, as levels may vary at this time. Sensitivity in the approach to the management of $\mathrm{FH}$ in children is vital, and parents and guardians should be kept fully informed and closely involved. Avoidance of smoking in children should be stressed, and good dietary and lifestyle approaches encouraged. ${ }^{3}$

\section{Specialist support}

Most patients diagnosed with $\mathrm{FH}$ in primary care can be managed by their general practitioner, especially if asymptomatic LDL-C levels are well controlled, and the patients' dietary and lifestyle compliance is good..$^{4,6,9,10}$

Pregnant women and children need specialist support and advice from early stages. ${ }^{2-4}$ Similarly, specialist involvement and support will be required for all patients who develop CVD symptoms or who have difficulty lowering LDL-C levels, poor compliance with diet and medications or ongoing side effects with medications. ${ }^{2-6}$

\section{Care plans}

Because FH is a hereditary, lifelong condition likely to result in premature CHD or death unless properly managed, affected patients should have care plans developed to maximise best practice approach to treatment. ${ }^{8}$ Specialist lipidologist support in addition to allied health support can be invaluable for many patients, especially if they find their condition difficult to manage or are poorly compliant with advice. ${ }^{8}$

\section{Use of cardiovascular disease risk calculators}

The use of Absolute Cardiovascular Disease Risk Assessment tools are best avoided in patients with suspected FH. These patients are already at increased risk of $\mathrm{CHD}$, and the relative risk from their lifelong cholesterol burden is so great that it overrides all other risk factors. ${ }^{5,8}$

\section{Conclusions}

Primary care physicians are uniquely placed to play an active part in detection and management of $\mathrm{FH}$, but greater public and health professional awareness of the condition is needed. The cholesterol burden present from birth can be missed if the familial, hereditary nature of the disorder is not considered. Left untreated, FH accelerates the onset of CAD by 3-4 decades. FH may be masked if statin therapy is instituted before considering a potential hereditary cause for raised LDL-C levels. Outcomes are good if treatment starts early and adherence is lifelong.

\section{Key points}

- FH is a hereditary condition affecting one in 250 patients ( $50 \%$ of first-degree relatives).

- The cholesterol burden present from birth accelerates the onset of CVD.

- Diet and lifestyle modifications alone are not sufficient for management.

- Greater awareness of FH by health professionals and the public is needed.

- National Institute for Health and Clinical Excellence guidelines recognise $\mathrm{FH}$ as an exemplar for personalised medicine.

- There are unique opportunities for primary care physicians to have a more active role in managing $\mathrm{FH}$.

\section{Authors}

Tom Brett FRACGP, MD, MA, Professor and Director General Practice and Primary Health Care Research, School of Medicine, The University of Notre Dame Australia,WA.tom.brett@nd.edu.au
Diane Arnold-Reed PhD, Research Development Coordinator, General Practice and Primary Health Care Research, School of Medicine, The University of Notre Dame Australia, WA Competing interests: None.

Funding: The article is based on information disseminated to participants in a study funded by a National Health and Medical Research Council (NHMRC) Partnership Grant (GNT1142883). SanofiAventis Australia Pty Ltd was a co-investigator on the Investigator Sponsored Study Grant (study number DIREGL07823). Financial support was provided by Amgen to allow travel to, and attendance and accommodation at, the European Atherosclerosis Society meeting in Brisbane, Australia, in May 2018 and the Familial Hypercholesterolaemia Summit in Melbourne, Australia, in February 2019.

Provenance and peer review: Not commissioned, externally peer reviewed.

\section{Acknowledgements}

Photographs were supplied by Professor GF Watts, School of Medicine, University of Western Australia and Lipid Disorders Clinic, Department of Cardiology, Royal Perth Hospital, Perth Australia.

\section{References}

1. Austin MA, Hutter CM, Zimmern RL, Humphries SE. Genetic causes of monogenic heterozygous familial hypercholesterolemia: A HuGE prevalence review. Am J Epidemiol 2004;160(5):407-20. doi: 10.1093/aje/kwh236.

2. Nordestgaard BG, Chapman MJ, Humphries SE, et al. Familial hypercholesterolaemia is underdiagnosed and undertreated in the general population: Guidance for clinicians to prevent coronary heart disease. Eur Heart J 2013;34(45):3478-90. doi: 10.1093/eurheartj/eht273.

3. Wiegman A, Gidding SS, Watts GF, et al. Familial hypercholesterolaemia in children and adolescents: Gaining decades of life by optimizing detection and treatment. Eur Heart J 2015;36(36):2424-37. doi: 10.1093/eurheartj/ehv157.

4. Watts GF, Sullivan DR, Poplawski N, et al. Familial hypercholesterolaemia: A model of care for Australasia. Atheroscler Suppl 2011;12(2): 221-63. doi: 10.1016/j.atherosclerosissup.2011.06.001.

5. National Institute for Health and Clinical Excellence. Familial hypercholesterolaemia: Identification and management. Clinical guideline [CG71]. NICE: London, 2018. Available at www.nice.org.uk/guidance/CG071 [Accessed 26 June 2019].

6. Watts GF, Gidding S, Wierzbicki AS, et al. Integrated guidance on the care of familial hypercholesterolaemia from the International FH Foundation. Int J Cardiol 2014;171(3):309-25. doi: 10.1016/j.ijcard.2013.11.025.

7. Austin MA, Hutter CM, Zimmern RL, Humphries SE. Familial hypercholesterolemia and coronary heart disease: A HuGE association review. Am J Epidemiol 2004;160(5):421-29. doi: 10.1093/aje/kwh237.

8. Brett T, Qureshi N, Gidding S, Watts GF. Screening for familial hypercholesterolaemia in primary care: Time for general practice to play its part. Atherosclerosis 2018;277:399-406. doi: 10.1016/j.atherosclerosis.2018.08.019.

9. Lan NSR, Martin AC, Brett T, Watts GF, Bell DA. Improving the detection of familial hypercholesterolaemia. Pathology 2019;51(2):213-21. doi: 10.1016/j.pathol.2018.10.015.

10. Bell DA, Kirke AB, Barbour R, et al. Can patients be accurately assessed for familial hypercholesterolaemia in primary care? Heart Lung Circ 2014; 23(12): 1153-57. doi: 10.1016/j. hlc.2014.06.015. 